University of Nebraska - Lincoln

DigitalCommons@University of Nebraska - Lincoln

Spring 2002

\title{
Multiple Creativities? Investigating Domain-Specificity of Creativity in Young Children
}

Ki-Soon Han

University of Incheon, Korea

Christine Marvin

University of Nebraska - Lincoln, cmarvin1@unl.edu

Follow this and additional works at: https://digitalcommons.unl.edu/specedfacpub

Han, Ki-Soon and Marvin, Christine, "Multiple Creativities? Investigating Domain-Specificity of Creativity in Young Children" (2002). Special Education and Communication Disorders Faculty Publications. 90. https://digitalcommons.unl.edu/specedfacpub/90

This Article is brought to you for free and open access by the Department of Special Education and Communication Disorders at DigitalCommons@University of Nebraska - Lincoln. It has been accepted for inclusion in Special Education and Communication Disorders Faculty Publications by an authorized administrator of DigitalCommons@University of Nebraska - Lincoln. 


\section{Multiple Creativities? Investigating Domain-Specificity of Creativity in Young Children}

\author{
Ki-Soon Han \\ University of Incheon, Korea
}

\author{
Christine Marvin \\ University of Nebraska-Lincoln
}

\begin{abstract}
One of the most controversial issues in contemporary research on creativity-whether a person's creativity is domain-specific or domain-general-was investigated with 109 second-grade children. The purposes of this study were to (1) provide empirical support for the domain-specific theory of creativity, (2) show relationships among children's creative performances as measured by three product-based assessments in three domains (storytelling, collage making, and math word problems), and (3) explore the relationship between children's creative performances and their general creative thinking skills, as measured by the Wallach-Kogan Creative Thinking Test and the Real- World Divergent Thinking Test. The findings of this study support the position of domain-specificity of creativity. Children exhibited a range of creative abilities across different domains, rather than a uniform creative ability in diverse domains, indicating there is considerable intra-individual variation in creative ability by domain. Divergent thinking measures in this study did not predict creative performance in at least two of three, if not all, domains assessed in the study. Implications of the study in connection with educational practices for gifted children are discussed.
\end{abstract}

$\mathrm{T}$ he supposition that human creativity is a generalized ability-similar irrespective of the kind of discipline or subject matter involved-has guided much of the research and theory development in the study of creativity over the last 50 years (Barron, 1988; Guilford, 1967; Hocevar, 1980; Milgram \& Milgram, 1976; Plucker, 1998; Runco, 1986; Torrance, 1966, 1988). Many researchers today still propose that creativity is applicable across domains or disciplines (Feldhusen \& Goh, 1995; Kay \& Rogers, 1998; Taylor, 1988; Torrance, 1988). However, some recent research has argued against the existence of general creative thinking skills, and skepticism is growing toward the domain-general theory of creativity (Baer, 1993; Csikszentmihalyi, 1990; Feldman, 1980;
Gardner, 1983, 1993a, 1993b; Kay \& Rogers, 1998; Matthew, 1990; Tardif \& Sternberg, 1988; Weisberg, 1993).

A paradigm shift toward a domain-specific view of creativity is occurring in the study of creativity. Recent theoretical (Csikszentmihalyi, 1988; Feldman, 1980, 1982, 1994; Gardner, 1983) and empirical (Baer, 1991, 1993) literature suggests that creativity may be a more specific trait than was once believed. Wallach (1985) indicated that developmental research on creativity is undergoing a shift away from the general toward the specific view and suggested that giftedness as well as creativity are much more domain-specific than was first understood. The recent focus on domain-specific knowledge

\section{Putting the Research to Use}

The results of this study suggest at least five practical implications for educators.

First, using multiple assessments in diverse domains and performance-based assessments within real learning contexts are essential to assessing properly the different kinds of creative abilities in various children.

Second, relying only on divergent thinking tests to identify creative children should be avoided.

Third, educators should make a greater effort to develop appropriate means for assessing and validating diverse creative abilities.

Fourth, individualized and domain-based teaching approaches, coordinated with current programs for teaching thinking skills or problem-solving skills, are necessary to address the increasing diversity in our school systems. Focusing less on labeling (Who is not creative?) and more on assessment diagnosis of children's abilities and needs is also helpful.

Fifth, intensive teacher training on attitudes toward the definition of and criteria for creativity and for the use of alternative or nontraditional assessments of creativity in children are essential to connect research and practice. 
has been regarded as the most dramatic shift to date in the study of creativity and giftedness (Feldman, 1994; Runco \& Nemiro, 1994).

Driving this philosophical shift has been an increasing objection to the heavy emphasis placed on divergent thinking measures as an index of a general capacity for creativity (e.g., Anastasi, 1982; Baer, 1991, 1993; Brown, 1989; Milgram, 1990; Runco \& Nemiro, 1994). Although divergent thinking tests may predict creative achievement under some conditions, the validity of these tests has been questioned because of the concern that high scores may not always predict creative achievement (e.g., Baer, 1993). There is also limited convincing evidence that children judged creative in one domain/discipline necessarily display strong divergent thinking skills (Gardner, 1993a, 1993b). Researchers have started to report that divergent thinking cannot be equated with creativity and that individual knowledge domains do play an important role in understanding and measuring creativity (Csikszentmihalyi, 1990; Feldman, 1980; Gardner, 1983).

Divergent thinking might not be as valid as we have thought (Hong \& Milgram, 1991; Runco, 1993). However, some recent research on divergent thinking has reported quite respectable predictive validity coefficients (Runco), which suggests that divergent thinking can be a useful estimate of potential for some creative and original performances. Runco also warned that researchers who regard divergent thinking as entirely invalid or unimportant may be ignoring recent empirical research.

Conclusions, therefore, about creativity's domaingenerality and -specificity remain inconsistent, inconclusive, and not clear-cut at all. Studies lack a clear and agreed upon result and conclusion and are open to a plethora of individual interpretations. Creativity has been argued as domain-general, as domain-specific, or as both depending upon the restricted theory, database used, or both. For example, some contemporary researchers of creativity seem to agree on the domain-specificity of creativity at least theoretically (Csikszentmihalyi, 1990; Gardner, 1993a, 1993b); however, their position lacks sufficient empirical support. There also have been research studies that introduced creativity as both a domain-general and -specific construct and empirically distinguished them (Hong, Milgram, \& Gorsky, 1995), but their conclusions lacked solid theoretical foundations and further research support. Finally, the dichotomy in research findings may be caused by methodological problems, such as methods and statistics used. Bivariate analyses appear to favor specificity while multivariate analyses tend to find evidence for the domain-generality of creativity. Per- formance-based assessments often produce evidence of specificity, while self-report scales suggest evidence for generality. In sum, the rush to characterize creativity as domain-general or -specific may be premature because of selective interpretation of theory, significant methodological limitations, and circuitous logic (Plucker, 1998). Further evidence is needed to inform the debate.

\section{Rationale and Purpose of the Study}

The domain-specific view of creativity was influenced strongly by the multiple intelligences theory in which Gardner (1983) proposed seven (later eight) distinct kinds of intelligences or domains of cognitive activity. Gardner (1988) suggested that we should no longer speak of an individual as being creative; instead, we should make an effort to recognize the possibility of a person's creativity in specific domains. Some educators in the field of gifted education have adopted Gardner's view and have begun to consider giftedness as "domainspecific and not simply a general indicator of intellectual ability" (Feldman, 1994, p. 8). Although several intelligence and measurement researchers have cautioned educators that multiple intelligences theory still has relatively little research support (Matthew, 1988), Gardner's view is well accepted among some gifted educators because it emphasizes the breadth, pluralism, and diversity of individuals' competencies.

The issue of the domain-specificity or -generality of creativity is important and controversial because it has broad implications for the identification of and educational practices used with creative children. For example, denying the domain-general approach to creativity is similar to denying the existence of general creative thinking skills and, therefore, is equal to denying the importance of divergent thinking in understanding and assessing creativity. Such a view is a huge threat to the most current practices used for identifying creativity and giftedness in school-age children (Baer, 1993). Because no clear definition of creativity dominates the literature, many professionals have used divergent thinking ability to define creativity. The terms creativity and divergent thinking may even be used rather interchangeably. Some educators believe that creativity is what divergent thinking tests measure, as intelligence is what an intelligence test measures.

Baer (1994a) pointed out that each year millions of children take general creative thinking tests, such as divergent thinking tests, under the assumption that creativity is a general trait that runs across diverse domains 
and that the identification of highly divergent thinkers is equivalent to identifying creative learners. Furthermore, some researchers still advocate using these tests for selection of gifted students and as outcome measures for evaluating creativity training programs (Cramond, 1994). If the assumption that creativity is domain-general is wrong, the current educational practice for identifying creative children is both "a waste of educational resources and an unfair basis for making placement decisions" (Baer, p. 80). In addition, the domain issue of creativity also has numerous implications for the design of educational programs that attempt to stimulate or enhance children's creative abilities (Plucker, 1998). If creativity is a domain-general trait, training of general creative skills will be an effective way to enhance children's creative abilities. On the contrary, if creativity is domain-specific, children's individual creative abilities will be best fostered within the context of particular talent areas (Plucker). For these reasons, Plucker suggested that research on the domain-generality and domain-specificity of creativity is necessary, important, and should continue.

Furthermore, although there is a growing interest in the domain-specific theory of creativity, the research supporting this view still remains quite limited (Baer, 1998; Bamberger, 1990; Plucker, 1998; Tardif \& Sternberg, 1988). Authors who support a domain-specificity view of creativity have not always addressed their arguments in a thoroughly convincing manner (Kogan, 1994; Plucker), and most studies exploring this issue have been limited in several ways.

First, most studies that have explored the domain issue of creativity have been limited to the use of a selfreport scale as a measure of creative performance in diverse domains, resulting in support for creativity's domain-generality (Hocevar, 1980; Milgram \& Milgram, 1976; Runco, 1986, 1987). Although some researchers suggest that self-report scales are conceptually and psychometrically reasonable measures, especially when the creative accomplishment is measured (Hocevar), self-report scales have been criticized for their lack of reliability and validity in assessing creative abilities (especially in young children; Brown, 1989). Performance-based or product-based assessments using expert consensus (Amabile, 1983, 1996) have been strongly recommended instead for assessing children's creative abilities in diverse domains. Although performance-based assessment is not without its problems, such as a lack of generality, increased cost, more involved scoring, and so on, performance-based assessment is well accepted because it embeds assessment in meaningful, intelligence-fair, real-world activ- ities. However, few studies to date have used performance-based assessments; those that have were limited to a single or a few performance-based assessments in one or two domains. In addition, very few studies have used expert consensus in evaluating children's performance-based products to explore the question of creativity's domain-specificity or -generality.

Second, although researchers have shown interest in looking at the relationship between divergent thinking and creative performances, few studies have paid attention to the relationships among children's diverse creative performances in diverse domains. Researchers have been mainly interested in criterion-related validity (concurrent or predictive) of divergent thinking measures in predicting creative performances. However, exploration of interrelations among a person's creative performances in different domains is essential in investigating the question of the domain-specificity and -generality of creativity.

Third, no study to date has utilized a battery of divergent thinking tests to explore the domain-specificity and domain-generality issue. Most studies have relied on a single divergent thinking test, thereby lacking the support of an adequate database. Since the correlations among various divergent thinking tests suggest that each taps various aspects of divergent thinking (Kogan, 1994), the use of a battery of divergent thinking tests would be necessary for careful examination of the domain issue.

Fourth, it has been suggested that divergent thinking tests would be more predictive of real-world creative performances if they contained problems children might encounter in their school or home settings (Hong \& Milgram, 1991; Okuda, Runco, \& Berger, 1991; Runco, 1993; Runco \& Okuda, 1988). However, the studies utilizing real-world divergent thinking tasks have correlated results only with self-report scales as measures of creative performances in diverse domains. There has been no published study that looks at the relationship between a real-world divergent thinking test and children's creative performances in diverse domains utilizing performance-based assessments.

Finally, most studies in this area have involved older subjects (e.g., high school students, college students). Published studies on young children (age 3-8 years) in this area have been meager (Godwin \& Moran, 1990; Hennessey \& Amabile, 1988) and limited to small sample sizes (e.g., Baer, 1991). Since early identification and early nurturing of creative children are believed essential for optimal educational and social outcomes of gifted children (Milgram, 1990), examination of this issue with younger and larger samples is important. 
Thus, the purpose of the present study was to investigate the issue of the domain-specificity and domaingenerality of creativity in young children. To examine this issue, this study explored (1) the relationships among children's creative performances in three domains and (2) the relationships between children's general creative thinking skills and children's creative performances in three domains. Children's performances in language, art, and math domains were judged by nine expert judges who rated children's creativity in storytelling, collage-making, and math word-problem-creating tasks. Children's general creative thinking skills were assessed by a battery of two divergent thinking tests, including subtests of the Wallach- Kogan Creativity Test (Wallach \& Kogan, 1965) and the Real World Divergent Thinking Test adapted from the work of Okuda, Runco, and Berger (1991).

\section{Method}

\section{Subjects}

One-hundred and nine second-grade children from five urban elementary schools, $53(49 \%)$ boys and 56 $(51 \%)$ girls, participated in the present study. The age range of the subjects varied from 7.01 (85 months) to 8.09 (104 months) years, with a mean of 7.10 years (93.7 months) and a standard deviation of 4.4 months.

\section{Instruments}

Wallach-Kogan Creativity Test. Two verbal subtests (Alternate Uses and Similarities) and one nonverbal subtest (Pattern Meanings) of the Wallach-Kogan Creativity Test were selected for the present study. Each verbal or nonverbal subtest had three items in it. In addition, the Wallach- Kogan Creativity Test was modified to include problem-finding tasks. It has been suggested that problem-finding tasks enhance the validity of divergent thinking tests as measures of creativity (Wakefield, 1985, 1992). Therefore, three items in each subtest were composed of two problem-solving tasks and one problem-finding task. The problem-solving tasks in each subtest asked children to tell all the different ways they could use an object, how two objects are alike, or all the things a pattern could be. The problem-finding task in each subtest asked children to generate a problem and then provide a solution to it. For example, a problemfinding task in the Pattern Meanings subtest was "Here is a blank card and a pencil. Make a pattern of your own, then tell me all the different things it could be."
Scoring followed the standard scheme suggested in the test manual. Fluency (number of responses) and originality (number of unique responses) scores for each problem- solving task and a fluency score for each problem-finding task were generated. The scores were summed across the subtests to yield scores for WallachKogan problem-solving fluency (WKF), problem-solving originality (WKO), and problem-finding fluency (WKPF).

Real- World Divergent Thinking Test. A Real-World Divergent Thinking Test, adapted from Okuda, Runco, and Berger (1991), was used in this study. The adaptation for the present study contained situations and problems relevant for second-grade children. In this study, four real-world divergent thinking tasks (two problem-solving and two problem-finding tasks) were used. All tasks were related to a school situation. In the real-world problem-solving tasks, students heard problems related to school life read aloud by the examiner. Students were asked to provide as many solutions as possible. For the real-world problem-finding tasks, students heard problematic vignettes about school life and were asked to list all the problems they could think of in each of these settings. The problem-solving tasks were scored for fluency (number of responses given, RWF) and originality (number of unique responses produced by less than $5 \%$ of children in the sample, RWO), and the problem-finding tasks were scored only for fluency (RWPF). Scoring for the Wallach- Kogan Creativity Test and the Real-World Divergent Thinking Test was done by the first author and two trained graduate students. The agreement between the three scorers was $95 \%$ or higher across all subtests of the two divergent thinking tests.

Performance-based assessments. Three performancebased assessments were utilized in this study. The three assessments included: a storytelling task (language), a collage-making task (art), and a math word-problem task (math). All tasks were selected from various sources using Amabile's $(1983,1996)$ guidelines for selecting appropriate tasks for a consensual assessment. Amabile (1996) indicated that an appropriate task for a consensual assessment should meet the following requirements: (1) the task must lead to some product that can be available to appropriate judges for evaluation, and (2) the task should be open-ended enough to permit flexibility and novelty in children's responses.

The storytelling and the collage-making tasks for the present study were developed by Amabile (1983), and have been validated in more than 30 independent studies by Amabile $(1983,1996)$, her colleagues, and others (Baer, 1991, 1993). High interrater reliability and long- 
term validity have been reported for these tasks (Amabile, 1983, 1996; Bear, 1994b). For the storytelling task, each individual child was shown the picture book $A$ Boy, a Dog, a Frog, and a Friend (Mayer, 1971). After looking through it to become familiar with the story, the child was asked to tell a story in his or her own words by saying one thing about each page while looking at the book's pictures. For the collage-making task, each child was given identical sets of materials to work with: a $14^{\prime \prime} \times 22^{\prime \prime}$ piece of white tag board, a bottle of glue, and a set of more than 100 precut pieces of construction paper in several different sizes, shapes, and colors. Each child was asked to make an interesting, silly design using all the materials provided.

The math word-problem task was adapted from Baer's (1991) study, where high interrater reliability information was reported. For the math word-problem task, children were asked to tell an interesting and original math word problem. Children were not asked to solve the problem they created, but instructed to make sure all needed information was included so that the problem could be solved by someone else. Children were instructed that they could use paper and pencil to create their math problems.

All performance-based assessments were judged for their creativity by nine expert judges (three judges in each domain) selected for this study. Based on Amabile's (1996) guidelines on consensual techniques for creativity assessment, judges were selected based on their experience and expertise in each domain. For each domain, teachers who had specialized credentials and at least five years of experience in teaching children's creative writing, art, or math were selected as judges for the study. To avoid any biases (e.g., settings, time of the day, moods, etc.) in scoring, all judges gathered at the same place and at the same time for four hours and had no knowledge of the identity of the author of each product. Each judge made his or her assessment independently in a separate room and rated children's products on a 1.0 (low) to 5.0 (high) numerical scale based on his or her own definition of creativity. As recommended by Amabile (1983, 1996), judges were not trained to agree with one another, nor given specific criteria for creativity. However, judges were instructed to rate children's products relative to other students' products of the task examined, rather than rating them against some absolute standards. Amabile suggested this is important because the levels of creativity produced by the ordinary children would be low in comparison with the greatest works produced in that domain. Once the judgments in all performancebased assessments were completed, the judges' ratings on each assessment were analyzed for interjudge reliability. Children's scores on each assessment were calculated by averaging the three judges' ratings. Judges were paid for their work in this study.

\section{Procedures}

All the measures, except one performance-based assessment, were administered individually and untimed. A small, quiet, and simply decorated room in each participating school was used to carry out each individually administered assessment. The examiner made an effort to establish rapport with each child in the assessment setting before the assessment was undertaken, and all the measures were administered in a game-like atmosphere. In most cases, all measures were administered during one session in about a 30-minute to 1-hour time period. To avoid any order effect in the administration procedure, all measures were administered in the same sequence with the Wallach-Kogan Creativity Test given first, followed by the Real-World Divergent Thinking Test, storytelling, and math word-problem. If the child displayed some fatigue or disinterest during the testing, testing was stopped and administered at another time. One performance-based assessment, collage making, was administered in a small-group setting at a time convenient to classroom teachers. All assessments were coded by number, not by child's name or child's ID, to avoid any biases in scoring.

\section{Results}

\section{Divergent Thinking Skills}

The reliability of each divergent thinking test was evaluated with inter-item correlations (Cronbach's alpha). Alpha coefficients were calculated for each subtest score of the Wallach-Kogan Creativity Test and the Real-World Divergent Thinking Test, respectively. The alpha coefficients for the Wallach-Kogan Creativity Test and the Real-World Divergent Thinking Test were quite high and all adequate. Table 1 presents the alpha coefficients with the means, standard deviations, and range of subtest scores for the two divergent thinking tests used in the study. Pearson correlation was used to examine the within and between relationships of the two divergent thinking tests. Table 2 presents these results. The Wallach-Kogan Creativity Test subtest scores, problem-solving fluency (WKF), problem-solving originality $(\mathrm{WKO})$, and problem- finding fluency (WKPF) were strongly and significantly related to each other. Simi- 
larly, the Real-World Divergent Thinking Test subtest scores were also significantly related to each other, except the relationship between the problem-solving originality score (RWO) and problem-finding fluency score (RWPF; $r=.206$ ). Furthermore, all subtest scores of the Wallach-Kogan Creativity Test were significantly related to the scores of the Real-World Divergent Thinking Test.

\section{Creative Performances}

Likewise, interjudge reliabilities were calculated for the storytelling, collage-making, and math word-problem-creating tasks using the Cronbach's coefficient alpha. As shown in Table 3, interjudge agreement among the three judges in each domain was fairly high in this study. Ensuring high interjudge reliability is the most important criterion of a consensual assessment procedure, since interjudge reliability in a study like this is equivalent to construct validity (Amabile, 1996).

\section{Is Creative Performance in One Domain Predictive of Performance in Other Domains?}

Pearson correlations were conducted to explore the relationships among the three performance-based assessments of storytelling, collage making, and the math word-problem. Among the three performance-based assessments, the only significant relationship was found between the storytelling and the math word-problem $(r=.283, p=.004)$. However, storytelling was not significantly related to collage making, nor was the math word-problem related to collage making. Although statistically significant, the correlation between the storytelling and math tasks was relatively weak $(r=.283)$, and the weak correlation made it difficult to predict one task from the other. Table 4 shows the correlations among the three performance-based assessments for the 109 children.

\section{Do General Creative Thinking Skills Predict Creative Performances?}

Several statistical analyses were conducted to examine the relationship between the two divergent thinking tests used in this study and the three performance-based assessments. First, Pearson correlation analyses were conducted to examine the relationships between the Wallach-Kogan Creativity Test (WK), the Real-World Divergent Thinking Test (RW), and the three performance-based assessments. Table 5 presents the detailed results.
Table 1. Mean, Standard Deviation, Range, and Alpha Coefficient for Subtest Scores of the WallachKogan Creativity Test and the Real-World Divergent Thinking Test

\begin{tabular}{|c|c|c|c|c|}
\hline Measures & M & SD & Range & Alpha \\
\hline \multicolumn{5}{|l|}{ Wallach-Kogan } \\
\hline \multicolumn{5}{|c|}{ Problem-solving tasks } \\
\hline Fluency & 36.60 & 20.209 & $9-101$ & .93 \\
\hline Originality & 5.62 & 6.33 & $0-34$ & .84 \\
\hline \multicolumn{5}{|c|}{ Problem-finding tasks } \\
\hline Fluency & 23.33 & 11.87 & $8-69$ & .77 \\
\hline \multicolumn{5}{|l|}{ Real-World } \\
\hline \multicolumn{5}{|c|}{ Problem-solving tasks } \\
\hline Fluency & 9.20 & 6.82 & $1-43$ & .94 \\
\hline Originality & 1.01 & 2.48 & $0-13$ & .90 \\
\hline \multicolumn{5}{|c|}{ Problem-finding tasks } \\
\hline Fluency & 11.25 & 9.42 & $0-60$ & .89 \\
\hline
\end{tabular}

Two of the six subtest scores of the two divergent thinking tests were significantly related to the storytelling task $(p<.01)$. The highest correlation existed for the Wallach-Kogan problem-solving originality score (WKO; $r=.365$ ). No significant relationship was found between any of the subtest scores of the two divergent thinking tests and the math word-problem task or collage-making tasks.

Multiple regression analyses were also conducted to examine how much of the variances for the three performance- based assessments were explained by the six subtest scores of the Wallach-Kogan and the Real-World Divergent Thinking Tests. Examination of the regression analysis reveals that the six subtest scores of the two divergent thinking tests did not explain significant nor substantial proportions of the variances (at $p<.01$ level) in any of the three performance-based assessments. The results indicated, however, that the six subtest scores of the two divergent thinking tests accounted for a marginally significant $14 \%(p=.02)$ of the variance in the storytelling task. The six subtest scores accounted for only $8 \%$ of the variance in the collage-making and $5.7 \%$ in the math word-problem tasks.

The results were similar when multiple regression analyses were conducted for each divergent thinking test. Specifically, the three subtest scores of the WallachKogan Creativity Test accounted for about 13.6\% ( $p=$ .002 ) of the variance in storytelling, $4.3 \%$ in math, and only $2.7 \%$ in collage making. The three subtest scores 
Table 2. Pearson Correlations Between the Wallach-Kogan Creativity Test and Real-World Divergent Thinking Test $(N=109)$

\begin{tabular}{lllllll}
\hline & WKF & WKO & WKPF & RWF & RWO & RWPF \\
\hline WKF & 1.00 & $.746^{*}$ & $.810^{*}$ & $.634^{*}$ & $.449^{*}$ & $.568^{*}$ \\
WKO & & 1.00 & $.595^{*}$ & $.510^{*}$ & $.524^{*}$ & $.331^{*}$ \\
WKPF & & 1.00 & $.558^{*}$ & $.365^{*}$ & $.601^{*}$ \\
RWF & & & 1.00 & $.640^{*}$ & $.369^{*}$ \\
RWO & & & & 1.00 & .206 \\
RWPF & & & & & 1.00 \\
\hline
\end{tabular}

$\mathrm{WKF}=\mathrm{WK}$ problem-solving fluency; $\mathrm{WKO}=\mathrm{WK}$ problem-solving originality; $\mathrm{WKPF}=\mathrm{WK}$ problem-finding fluency; RWF = RW problem-solving fluency; RWO = RW problem-solving originality; RWPF = RW problem-finding fluency

$* p<0.01$

Table 3. Mean Ratings, Standard Deviations, and Alpha Coefficient for the Three Performance-Based Assessments ( $N=109)$

\begin{tabular}{lllc}
\hline Tasks & M $^{*}$ & SD & Alpha \\
\hline Storytelling & 2.37 & 1.12 & .88 \\
Collage making & 2.91 & 1.21 & .94 \\
Math word-problem & 2.26 & 1.25 & .92 \\
\hline
\end{tabular}

* Rating: 1 (not creative) to 5 (highly creative).

of the Real- World Divergent Thinking Test did not explain a significant proportion of the variances in any of the three performance- based assessments, but accounted for only a marginally significant $8 \%(p=.04)$ of the variance in storytelling, $5.1 \%$ in collage making, and $1.4 \%$ in math word-problem tasks.

Although the multiple regression analysis provides information about the extent to which the WallachKogan Creativity Test and the Real-World Divergent Thinking Test explain and predict each dependent variable (performance-based assessments) separately, the procedure ignores the very essence and richness of a multifaceted phenomenon between the multiple dependent and independent variables. Canonical correlations, therefore, were used to demonstrate an interrelationship between these two sets of multiple variables.

Canonical analysis was conducted to explain the extent to which one set of criterion variables (storytelling, collage making, and math word-problems) were predicted or explained by another set of predictor vari-
Table 4. Pearson Correlations Between Storytelling, Collage Making, and the Math Word Problem ( $\mathrm{N}=$ 109)

\begin{tabular}{lccl}
\hline Tasks & $\begin{array}{l}\text { Story- } \\
\text { telling }\end{array}$ & $\begin{array}{l}\text { Collage } \\
\text { Making }\end{array}$ & $\begin{array}{l}\text { Math } \\
\text { Problem }\end{array}$ \\
\hline Storytelling & 1.00 & .072 & $.238^{*}$ \\
Collage making & & 1.00 & .195 \\
Math word-problem & & & 1.00 \\
\hline
\end{tabular}

$* p<0.01$

ables (the six subtest scores of the two divergent thinking tests). Results indicated that the predictor variate was not significantly correlated with the criterion variate $\left(R_{c}=.407, \mathrm{c}^{2}[100]=24.23, p=.148\right)$. Any combination of the six subtests did not explain or predict significantly any combination of the three performance-based assessments. The divergent thinking measures and the creative performances in three domains were independent of one another. Because no significant correlation was found between the two sets of variables, no further analysis was made.

\section{Discussion}

\section{Creativity as Domain-Specific}

The results of the study suggest that there is considerable intra-individual variation in creative ability by domain in the 109 second-grade children who participated 
Table 5. Pearson Correlations for the Wallach-Kogan Creativity Test, the Real-World Divergent Thinking Test, and Three Performance-Based Assessments $(N=109)$

\begin{tabular}{lllc}
\hline Measures & $\begin{array}{l}\text { Story- } \\
\text { telling }\end{array}$ & $\begin{array}{l}\text { Collage } \\
\text { Making }\end{array}$ & $\begin{array}{l}\text { Math } \\
\text { Problem }\end{array}$ \\
\hline WKF & $.306^{*}$ & .069 & .120 \\
WKO & $.365^{*}$ & .150 & .192 \\
WKPF & .231 & .073 & .135 \\
RWF & .243 & -.011 & .026 \\
RWO & .247 & .038 & .019 \\
RWPF & .157 & .197 & .116 \\
\hline
\end{tabular}

WKF = WK problem-solving fluency; $W K O=W K$ problem-solving originality; WKPF = WK problemfinding fluency; RWF = RW problem-solving fluency; RWO = RW problem-solving originality; RWPF $=\mathrm{RW}$ problem-finding fluency

$* p<0.01$

in the study. Children in the study exhibited a range of creative abilities across different domains, rather than a uniform creative ability in diverse domains. It is implied from the study that it is hard to predict reliably a child's creative ability in one domain based on his or her creative ability in other domains, thereby providing some support for the domain-specific theory of creativity.

Although a significant relationship existed between storytelling and math word-problem tasks in the whole sample of 109 children, the correlation between the tasks was weak $(r=.283)$ and not substantial at all. This weak but significant relationship might be explained in the fact that both tasks utilized a similar task format. In the storytelling task, children were asked to generate a story based on a wordless picture book, and in the math word-problem, children were asked to make up a math-related story problem. The fact that both tasks required verbal explanations might be responsible for the significant relationship between the storytelling and math word-problem tasks. The weak but significant relationship between the tasks also might be attributed to individual "style" that is defined as a manner of approaching and accomplishing tasks (Miller, 1991). As Adams (1993) suggested, the weak but significant correlation between such tasks may reflect the systematic influence of style, rather than links between the content areas themselves. Adams indicated that, if individuals adopt the same style in two different tasks, the positive and significant correlation between the tasks is the function of style, not a true reflection of association between different knowledge domains. However, whether the weak but significant correlation between the storytelling and math word-problem tasks is attributed to domain-general creative ability, similar task format, individual's style toward a task, or other affective factors that may cut across domains-such as creative self-efficacy or motivation-cannot be explained empirically in this study. Replication would be useful in examining whether similar patterns are found in further studies and in exploring possible causes for association between the tasks.

Taken together, these findings are in contrast to the previous research (e.g., Hocevar, 1980; Hong, Milgram, \& Gorsky, 1995) that suggested that creative performances in different domains for young children were significantly related to each other and rather domaingeneral. The results also stand out against the commonly held claim that children are creative in many different domains. These findings are, then again, consistent with some other earlier research (e.g., Baer, 1991) that suggested creative performances are domain-specific. By employing a large sample of 109 children and utilizing performance-based assessments (not depending on self-report scales) to assess creative ability in children, however, this study provides a more valid response to the controversial issue of the domain-specificity and -generality of creativity. Nevertheless, because no study to date (including this one) has found absolute independence or dependence between tasks in different domains, interpretation and conclusion regarding creativity's domain-generality and -specificity should be made very carefully.

\section{Divergent Thinking as a General Creative Thinking Ability}

One of the most striking findings of the study was that divergent thinking measures did not have great power in predicting creative performances in at least two of three, if not all, domains assessed in the study. Neither of the divergent thinking tests administered in the study, separately or in a battery, predicted real creative behaviors of 109 young children. The amount of variances explained by the two divergent thinking tests in the collage and math tasks were relatively small. Although two subtests of the Wallach-Kogan Creativity Tests were significantly related to the storytelling performance, the amount of variance explained by the two divergent measures, separately or in a battery, was not substantial. In creativity research, "good" test correlations with outside validating criteria run between .40 
and .65 because of the host of factors affecting test and criterion data (Bartlett \& Davis, 1974). None of the correlations between the two divergent thinking tests and the storytelling task reached this range of "good." More importantly, the canonical correlation indicated that the two divergent thinking tests and children's creative performances in the three domains were independent of one another.

The findings of the study both complement and contrast with earlier research. These findings are consistent with some of the previous research in that divergent thinking measures were often weakly but significantly related to creative activities in the language domain (i.e., storytelling, writing), but not to creative behaviors in other domains (Baer, 1991; Runco, 1986). The current results suggest a possible verbal bias in divergent thinking tests; however, the use of only one nonverbal subtest (from the Wallach-Kogan Creativity Test) in the present study may have contributed to these results.

The results also contrast with earlier research efforts (e.g., Bartlett \& Davis, 1974; Hocevar, 1980; Hong, Milgram, \& Gorsky, 1995; Torrance, 1972; Wallach \& Kogan, 1965; Wallach \& Wing, 1969) that have found significant relationships between divergent thinking measures and diverse creative performances (i.e., leadership, art, social service, literature, writing, math, science, crafts). As indicated, the contrast might be due to the fact that the earlier research has depended on self-report scales to measure children's creative performances in different domains. As indicated, self-report scales, however, have been criticized for their questionable validity and the response-set bias that may lead individuals to systematically underestimate or overestimate their creative behaviors across all domains (Baer, 1999).

Overall, these findings of the present study suggest the lack, if not absence, of general creative thinking skills in explaining children's creative performances. On the other hand, the results might be interpreted as saying that divergent thinking measures may not represent a general creative thinking ability appropriately. These findings have important practical implications, since divergent thinking tests are widely used to identify creative children in a wide variety of domains, and they are often regarded as a criterion, rather than a correlate or predictor of creative behavior.

Despite these findings, this study is admittedly limited in several ways. Children in the present study were assessed only once for their creative performances. It may be possible that creative performance measured at other times and in other settings will show different results. In addition, use of a single task to sample children's creative ability in each domain may not suffi- ciently reveal the children's true abilities for a given domain (Leondar, 1977). Use of at least two tasks in the same domain, gathering data through observation in class over time, or both could minimize any distortion that may happen during one-shot assessments and provide more valid evidences of creative performances across domains in young children. Furthermore, the adaptation of the divergent thinking tests used in the present study and the order of item administration may have affected the results of the present study. Replication of the study should be made to find any possible effects of these factors.

Better understanding of the domain-generality and -specificity of creativity might also be possible if separate additional analyses of creative and noncreative groups of children were used. Studying these groups separately for example, in examining the relationship between general creative thinking skills and creative performances would increase the understanding of the domain issue of creativity. Such analyses need large sample sizes and unfortunately could not be addressed in this study.

Future research should explore whether the "process" of creative performance in different domains is general or specific to a particular domain. Identifying the important (social/psychological) variables that influence creative performances in diverse domains in young children and how the variables interact with each other remains unknown. Finally, systematic observation of four groups of children who are both creative and divergent, who are creative but not divergent, who are not creative but divergent, and neither creative nor divergent would also provide interesting information for the domain issue of creativity.

\section{Implications of the Study}

One of the most critical issues in gifted education has been its failure to identify appropriately and plan adequately programs for all young gifted children. The major cause of our failure has been the procedure currently employed to assess and identify giftedness and creativity in our school systems. The findings of this study suggest that creative performances may be quite (but not absolutely) domain-specific in young children, and some divergent thinking tests (or subtests) as a measure of creative abilities in young children may not be as valid as we have thought. It is obvious from this study that there are various kinds of creativity, and it is hard to predict reliably a child's creative ability in one domain based on his or her creative ability in other do- 
mains or simply his or her divergent thinking test scores in all cases. This study clearly indicates that an appreciable number of children who score low on divergent thinking tests can be identified as "creative" by their creative performances using different measures of creativity. Furthermore, the results imply that we may overlook many extremely creative children and prevent their enrollment in gifted education programs if we establish a level on some single standardized measure of creativity without considering each child's performance strengths and weaknesses.

Use of multiple assessments in diverse domains and performance-based assessments within real learning contexts are essential to assessing properly the different kinds of creative abilities in various children. To accomplish this goal, however, more effort should be made to develop and validate appropriate means for assessing diverse creative abilities.

The proposed domain-specific approach in identifying creative children has various advantages over current identification procedures that are rooted in domain-general philosophy and depend on divergent thinking tests. Most of all, as Gardner (1983) once remarked, domain-specific views of creativity can help educators shift their interest from "How creative is she?" to "How is she creative?" By considering specific strengths of individual children, identification based on a domain-specific view can provide information about the nature of creative abilities revealed by a particular child that might, in turn, suggest how a program might be designed to challenge effectively the child's special abilities (Treffinger \& Feldhusen, 1996). Once the specific domains in which individual children demonstrate their creativity are found, Treffinger and Feldhusen have indicated that educational services and interventions can be focused more accurately and effectively on those, having two goals of "nurturing already recognized creativity in a specific domain" and "discovering/ developing new ones." So far, these great advantages of domain-specific approaches, however, have been ignored and overshadowed by the frequent use of divergent thinking tests with subsequent lack of applicability to instructional planning.

Recent research supports this position by confirming that specific interventions focused on specific domains are far more effective than general "gifted treatment," which usually offers "all-purpose" enrichment programs for all kinds of gifted children (Bloom, 1985; Csikszentmihalyi, Rathunde, \& Whalen, 1993; Treffinger \& Feldhusen, 1996). Enormous evidences have suggested that our gifted children are poorly served by standard enrichment programs that do not consider seriously their individuality (U.S. Office of Education, 1993). However, this is not arguing that we should abandon the current programs of teaching general thinking skills or problem-solving skills in our schools. Even with all the negatives mentioned on the above, there is no doubt that improving children's creative thinking and problem-solving abilities in diverse domains are essential educational goals (Treffinger, 1986; Treffinger \& Feldhusen, 1996). In fact, general creative thinking skills can and should continue to be encouraged in every domain and area of giftedness and talent. Individualized and domain-based approaches, coordinated with current programs for teaching thinking skills or problem-solving skills, however, may be the best way to address the increasing diversity in our school systems.

Currently, an extensive paradigm shift in the field of gifted education is occurring: the movement of "talent development" (Csikszentmihalyi, Rathunde, \& Whalen, 1993; Gagne, 1985; Renzulli, 1994; Treffinger, 1995; Treffinger \& Feldhusen, 1996; VanTassel-Baska, 1997). Educators of gifted children are being challenged to take account of the proposition that recognition and development of various talents among children are the most powerful contribution to education (Feldman, 1980; Treffinger, 1995). Clearly, the idea of domain-specificity of creativity seems to reflect this current trend, and the talent development approach firmly supports the identification and development of an individual child's creative ability in a particular domain. One main idea behind these new concepts is appreciating and responding to individual differences, thereby more broadly recognizing and developing many kinds of human strengths and talents.

In closing, the question of domain-generality and -specificity in cognitive abilities, including creativity, might not be the unanswerable riddle that Sternberg (1989) once mentioned it was. It is true, however, that it is a very complicated and difficult question. As Keating and Crane (1990) have noted, "dichotomies in thinking are sometimes useful, sometimes misleading, but apparently unavoidable" (p. 411). The evidences from this study and other research support the perspective that a domain-general view of creativity has often misguided the identification of and educational practices for our creative children. Domain-general views of creativity that seek to reinforce the "generality," rather than viewing it the other way around, are too limited, but have been maintained for the sake of today's status quo in identifying creative children in our school systems. A domain-specific view may offer more useful, flexible, and reasonable directions for identifying and educating creative potentials for their optimal developments. 


\section{References}

Adams, M. (1993). An empirical investigation of domain-specific theories of preschool children's cognitive abilities. Unpublished doctoral dissertation, Tufts University, Medford, MA.

Amabile, T. M. (1983). The social psychology of creativity: A componential conceptualization. Journal of Personality and Social Psychology, 45, 357-376.

Amabile, T. M. (1996). Creativity in context. Boulder, CO: Westview Press.

Anastasi, A. (1982). Psychological testing. New York: Macmillan.

Baer, J. (1991). Generality of creativity across performance domains. Creativity Research Journal, 4, 23-39.

Baer, J. (1993). Creativity and divergent thinking: A taskspecific approach. Hillsdale, NJ: Erlbaum.

Baer, J. (1994a). Why you shouldn't trust creativity tests. Educational Leadership, 51, 80-83.

Baer, J. (1994b). Performance assessments of creativity: Do they have long-term stability? Roeper Review, 17, 7-11.

Baer, J. (1998). The case for domain specificity of creativity. Creativity Research Journal, 11, 173-177.

Baer, J. (1999). Domains of creativity. In M. A. Runco \& S. R. Pritzer, eds., Encyclopedia of creativity (Vol. 1, pp. 591-596). San Diego, CA: Academic Press.

Bamberger, J. (1990). Current views on research in creativity. Contemporary Psychology, 35, 434-435.

Barron, F. (1988). Putting creativity to work. In R. J. Sternberg, ed., The nature of creativity (pp. 76-98). New York: Cambridge University Press.

Bartlett, M. M., \& Davis, G. (1974). Do the Wallach-Kogan Creativity Tests predict real creative behavior? Perceptual and Motor Skills, 39, 730.

Bloom, B. S. (Ed.). (1985). Developing talent in young people. New York: Ballantine.

Brown, R. T. (1989). Creativity: What are we to measure? In J. A. Glover, R. R. Ronning, \& C. R. Reynolds, eds., Handbook of creativity (pp. 3-32). New York: Plenum Press.

Cramond, B. (1994). We can trust creativity tests. Educational Leadership, 52(2), 70-71.

Csikszentmihalyi, M. (1988). Society, culture, and person: A system view of creativity. In R. J. Sternberg, ed., The nature of creativity (pp. 325-339). New York: Cambridge University Press.

Csikszentmihalyi, M. (1990). The domains of creativity. In M. A. Runco \& R. S. Albert, eds., Theories of creativity (pp. 190-214). London: Sage.
Csikszentmihalyi, M., Rathunde, K., \& Whalen, S. (1993). Talented teenagers: The roots of success and failure. New York: Cambridge University Press.

Feldhusen, J. F., \& Goh, B. E. (1995). Assessing and accessing creativity: An integrated review of theory, research, and development. Creativity Research Journal, 3, 231-247.

Feldman, D. H. (1980). Beyond universals in cognitive development. Norwood, NJ: Ablex.

Feldman, D. H. (Ed.). (1982). New directions for child development: No. 17. Developmental approaches to giftedness and creativity. San Francisco: Jossey-Bass.

Feldman, D. H. (1994). Beyond universals in cognitive development (2nd ed.). Norwood, NJ: Ablex.

Gagné, F. (1985). Giftedness and talent: Reexamining a reexamination of the definitions. Gifted Child Quarterly, 29, 103-112.

Gardner, H. (1983). Frames of mind. New York: Basic Books.

Gardner, H. (1988). Creative lives and creative works: A synthetic scientific approach. In R. J. Sternberg, ed., The nature of creativity (pp. 298-324). New York: Cambridge University Press.

Gardner, H. (1993a). Multiple intelligence. New York: Basic Books.

Gardner, H. (1993b). Creating minds. New York: Basic Books.

Godwin, L. J., \& Moran, J. D., II. (1990). Psychometric characteristics of an instrument for measuring creative potential in preschool children. Psychology in the Schools, 27, 204-210.

Guilford, J. P. (1967). The nature of human intelligence. New York: McGraw-Hill.

Hennessey, B. A., \& Amabile, T. M. (1988). Story-telling: A method for assessing children's creativity. Journal of Creative Behavior, 22, 235-246.

Hocevar, D. (1980). Intelligence, divergent thinking, and creativity. Intelligence, 4, 25-40.

Hong, E., \& Milgram, R. M. (1991). Original thinking in preschool children: A validation of ideational fluency measures. Creativity Research Journal, 4, 253-260.

Hong, E., Milgram, R. M., \& Gorsky, H. (1995). Original thinking as a predictor of creative performance in young children. Roeper Review, 18, 147-149.

Kay, S. I., \& Rogers, K. B. (1998). Preface. Roeper Review, 21, 4 .

Keating, D. P., \& Crane, L. L. (1990). Domain-general and domain-specific processes in proportional reasoning. Merrill-Palmer Quarterly, 36, 411-424.

Kogan, N. (1994). Diverging from divergent thinking. 
Contemporary Psychology, 39, 291-292.

Leondar, B. (1977). Hatching plots: Genesis of storymaking. In D. Perkins \& B. Leondar, eds., The arts and cognition (pp. 172-191). Baltimore: Johns Hopkins University Press.

Matthew, D. J. (1988). Gardner's multiple intelligence theory: An evaluation of relevant research literature and a consideration of its application to gifted education. Roeper Review, 11, 100-104.

Matthew, D. J. (1990). Patterns of competence in early adolescence: A domain-specific approach to gifted education. Unpublished doctoral dissertation, University of Toronto.

Mayer, M. (1971). A boy, a dog, a frog, and a friend. New York: Dial Books for Young Readers.

Milgram, R. M. (1990). Creativity: An idea whose time has come and gone? In M. A. Runco, \& R. S. Albert, eds., Theories of creativity (pp. 215-233). London: Sage.

Milgram, R. M., \& Milgram, N. A. (1976). Creative thinking and creative performance in Israeli children. Journal of Educational Psychology, 68, 255-259.

Miller, A. (1991). Personality types: A modern synthesis. Calgary, Alberta, Canada: University of Calgary Press.

Okuda, S. M., Runco, M. A., \& Berger, D. E. (1991). Creativity and the finding and solving of real-world problems. Journal of Psychoeducational Assessment, 9, 45-53.

Plucker, J. (1998). Beware of simple conclusions: The case for content generality of creativity. Creativity Research Journal, 11, 179-182.

Renzulli, J. S. (1994). Schools for talent development: A practical plan for total school improvement. Mansfield Center, CT: Creative Learning Press.

Runco, M. A. (1986). Divergent thinking and creative performance in gifted and nongifted children. Educational and Psychological Measurement, 46, 375-384.

Runco, M. A. (1987). The generality of creative performance in gifted and nongifted children. Gifted Child Quarterly, 31, 121-125.

Runco, M. A. (1993). Divergent thinking, creativity, and giftedness. Gifted Child Quarterly, 37, 16-22.

Runco, M. A., \& Nemiro, J. (1994). Problem finding, creativity, and giftedness. Roeper Review, 16, 235-240.

Runco, M. A., \& Okuda, S. M. (1988). Problem discovery, divergent thinking, and the creative process. Journal of Youth and Adolescence, 17, 211-220.

Sternberg, R. J. (1989). Domain-generality versus domain-specificity: The life and impending death of a false dichotomy. Merrill-Palmer Quarterly, 35, 115-130.
Taylor, C. W. (1988). Various approaches to and definitions of creativity. In R. J. Sternberg, ed., The nature of creativity (pp. 99-124). New York: Cambridge University Press.

Tardif, T. Z., \& Sternberg, R. J. (1988). What do we know about creativity? In R. J. Sternberg, ed., The nature of creativity (pp. 429-440). New York: Cambridge University Press.

Torrance, E. P. (1966). Torrance tests of creative thinking. Bensenville, IL: Scholastic Testing Service.

Torrance, E. P. (1972). Predictive validity of the Torrance Tests of Creative Thinking. The Journal of Creative Behavior, 6, 236-253.

Torrance, E. P. (1988). Creativity as manifest in testing. In R. J. Sternberg, ed., The nature of creativity (pp. 4375). New York: Cambridge University Press.

Treffinger, D. J. (1986). Research on creativity. Gifted Child Quarterly, 30, 15-19.

Treffinger, D. J. (1995). School development, talent development, and creativity. Roeper Review, 18, 93-97.

Treffinger, D. J., \& Feldhusen, J. F. (1996). Talent recognition and development: Successor to gifted education. Journal for the Education of the Gifted, 19, 181-193.

U. S. Office of Education. (1993). National excellence: A case for developing America's talent. Washington, DC: U.S. Government Printing Office.

VanTassel-Baska, J. (1997). Response to "varieties of intellectual talent." Journal of Creative Behavior, 31, 125-130.

Wakefield, J. F. (1985). Toward creativity: Problem finding in a divergent-thinking exercise. Child Study Journal, 15, 265-270.

Wakefield, J. F. (1992). Creative thinking: Problem solving skills and arts orientation. Norwood, NJ: Ablex.

Wallach, M. A. (1985). Creativity testing and giftedness. In F. D. Horowitz \& M. O'Brian, eds., The gifted and talented: Developmental perspectives (pp. 99-124). Washington, DC: American Psychological Association.

Wallach, M. A., \& Kogan, N. (1965). Modes of thinking in young children. New York: Holt, Rinehart, \& Winston.

Wallach, M. A., \& Wing, C. W. (1969). The talented students: A validation of the creativity-intelligence distinction. New York: Holt, Rinehart, \& Winston.

Weisberg, R. W. (1993). Creativity beyond the myth of genius. New York: Freeman. 